\title{
CONSTRUÇÃO DAS IDENTIDADES DE JOVENS DE ORIGEM IMIGRANTE EM EUROPA: RESULTADOS DUM PROJETO EUROPEU
}

\author{
Beatriz Padilla* \\ Alejandra Ortiz**
}

Este artigo descreve e analisa alguns dos elementos que influenciam a construção das identidades dos jovens de origem imigrante na Europa. Os resultados derivam dum projeto de investigação europeu intitulado "Rumo à construção social duma juventude europeia: a experiência de inclusão e exclusão na esfera pública dos jovens migrantes de segunda geração" ${ }^{\prime 1}$, desenvolvido entre 2006 e 2009 em nove cidades localizadas em cinco países: Espanha (Madrid e Barcelona), Itália (Génova e Roma), Portugal (Lisboa e Porto), França (Metz), Alemanha (Berlim) e Holanda (Utrecht). A primeira parte analisa os dados quantitativos recolhidos nos contextos de estudo, comparando os jovens descendentes de imigrantes com os jovens autóctones, focando a questão da identidade como um assunto central no processo de inclusão dos jovens imigrantes. A segunda parte aborda alguns dos marcadores identitários presentes nos jovens descendentes de imigrantes em Portugal, à luz de dados etnográficos recolhidos especificamente para o caso dos jovens na Área Metropolitana de Lisboa focando as questões de identidade, género e discriminação.

Palavras chave: origem imigrante, descendentes de imigrantes, jovens, identidades, Portugal, Europa.

\section{Introdução}

Os jovens migrantes e descendentes de imigrantes (ou de origem imigrante) vão influenciar o futuro da Europa nas próximas décadas, dai que

\footnotetext{
* Instituto de Ciências Sociais, Departamento de Sociologia da Universidade do Minho. Lisboa/Portugal.

** Centro de Investigação e Estudos de Sociologia (CIES-IUL). Lisboa/Portugal.

1 N.T (do original): "Toward a social construction of an European youth: the experience of inclusion and exclusion in the public sphere among second generation migrated teenagers". Projeto do $6^{\mathrm{o}}$ Programa Quadro financiado pela Comisão Europeia, № 029105.
} 
a reflexão sobre o assunto não se trate dum tema menor. Esta realidade é uma consequência dos antigos e dos recentes processos migratórios, com os quais os países de União Europeia têm-se deparado, embora tenham decorrido e ainda decorram em diferentes momentos e intensidades. Na actualidade, a mediano e a longo prazo a questão das chamadas segundas (e terceiras) gerações, é ou virá a ser uma regularidade nas sociedades, colocando desafios de inclusão que devem ser resolvidos. Estes desafios são diferentes aos colocados pelas primeiras gerações. Como a literatura salienta, os imigrantes de primeira geração reconhecem-se a si próprios como estranhos nas sociedades de destino enquanto os seus filhos sentem-se vítimas do estranhamento, e lidam com esta situação recorrendo a diferentes estratégias e desenvolvendo diferentes processos de identificação ${ }^{2}$. Em primeiro lugar, os jovens descendentes não migraram por decisão nem necessidade própria, dai que a forma como vivem e sentem a relação com a sociedade de acolhimento é diferente a dos pais, embora varie nos distintos contextos. Em segundo lugar, e como consequência do enunciado, a formação das identidades e pertenças e os processos de identificação em relação ao país de origem dos pais e ao de acolhimento envolvem uma multiplicidade de factores e situações que desempenham um papel central na integração, aceitação e pertença às sociedades europeias.

A este cenário complexo, ainda se acrescenta o facto dos jovens e adolescentes serem uma categoria social determinante vinculada à mudança e à transição para a vida adulta, pelo que resulta necessário também analisar as identidades desde a exclusão e marginalização à qual se sujeitam estes jovens na sua dupla condição de jovens e de imigrantes ${ }^{3}$. Neste sentido, a condição de imigrante ou descendente de imigrante acrescenta-se à complexidade inerente à condição de jovem. A adolescência é descrita como um momento de "mudanças corporais, da expansão da independência e do aumento de auto-descobrimentos, muitas vezes caracterizado por uma série de desafios" ${ }^{\prime 4}$ que podem implicar riscos e oportunidades, ou ambos.

Se a uma etapa tão conturbada como a juventude e a adolescência, na qual a identidade é modelada de forma marcante, acrescentamos o facto

2 KOEFOED, Lasse e SIMONSEN, Kirsten. Rescaling identities: Embodied others and alternative spaces of identification.

3 PARELLA, Sónia. Desigualdades de Género. Jóvenes Inmigrantes; MELIA, Michael. Transatlantic Dialogue on Integration of Immigrant Children and Adolescents; COLOMBO, Enzo et alii. Different But Not Stranger: Everyday Collective Identifications among Adolescent Children of Immigrants in Italy; ORTIZ, Alejandra. Identidades, pertenças e afinidades dos jovens descendentes de imigrantes africanos na Área Metropolitana de Lisboa.

4 ROTH, Jodie e BROOKS-GUNN, Jeanne. What do adolescents need for healthy development? Implications for youth, p. 4. 
destes jovens serem considerados enquanto "filhos de", que é um status adscrito, contrário aos valores "modernos" que valorizam os status adquirido ou conseguido, apontados como ideais pelas instituições socializadoras, o resultado envolverá sempre uma carga negativa e estigmatizadora, tal como Bolzman, Fibi e Vial afirmaram:

Apesar do carácter polissémico do termo [segunda geração], as políticas de imigração reservam geralmente o seu uso para designar aos filhos dos trabalhadores imigrantes que nasceram o cresceram no país de residência dos seus pais, e nele residem. Largamente utilizada na linguagem corrente, esta categorização introduz concomitantemente também uma marca social e étnica. Isto, porque não se aplica a todos os filhos dos estrangeiros, e sim só aos nascidos de trabalhadores manuais que ocupam posições sociais subordinadas nas sociedades de acolhimento. Com isto, se sublinha a especificidade social e étnica não só em relação aos jovens autóctones, mas também em relação aos jovens estrangeiros nascidos em contextos mais privilegiados, sobre-entendendo que os imigrantes endógenos estão destinados a reproduzir o status ocupado pelos seus pais nas sociedades de acolhimento ${ }^{5}$.

Vários trabalhos criticam o conceito de segunda geração, especialmente no contexto europeu. No entanto a própria denominação não necessariamente altera o significado do assunto e os termos alternativos nem sempre conseguem uma mudança positiva na percepção sobre "ser" descendente de imigrantes ${ }^{6}$. A controvérsia terminológica configura-se mais como uma necessidade de protagonismo europeu ${ }^{7}$ em relação ao tema de estudo, liderado tradicionalmente pelos norte-americanos ${ }^{8}$. Na verdade é que nem as sociedades norte-americanas nem as europeias parecem ter aceite aos jovens descendentes como iguais. No entanto neste trabalho não usamos o conceito de segunda geração (salvo para a distinção como

5 BOLZMAN, Cláudio et alii. Secondas - Secondos. Le processus d'integration des jeunes adultes issus de l'immigration espagnole et italienne en Suisse, p. 20.

6 CASAS, Monserrat (ed.). També catalans: fills i filles de famílies immigrades; MACHADO, Fernando e MATIAS, Raquel. Descendentes de Imigrantes nas Sociedades de Acolhimento: Linhas de Identificação Sociológica; ESSOMBA, Miguel Angel et alii. Immigrant adolescents in Catalonia and the construction of cultural identity: Life stories and inclusion processes; GUALDA, Estrella. Segunda Generación y adolescents y jóvenes inmigrantes: el caso de Huelva; APARICIO, Rosa e TORNOS, Andrés. Hijos de inmigrantes que se hacen adultos: marroquíes, dominicanos y peruanos.

7 CRUL, Maurice et alii. The European Second Generation Compared. Does the Integration Context Matter?

8 PORTES, Alejandro (ed.) The New Second Generation; PORTES, Alejandro e RUMBAUT, Rubén (eds.). Legacies: The Story of the Immigrant Second Generation; PORTES, Alejandro et alii. La asimilación segmentada sobre el terreno: la nueva segunda generación al inicio de la vida adulta. 
categoria específica relativa ao tempo de residência e/ou país de nascimento): respeitando a vontade dos próprios jovens que rejeitaram dito conceito, adoptamos assim o de descendentes de imigrantes ou de origem imigrante.

Perguntamo-nos como se configura a identidade destes jovens residentes na União Europeia, entre um passado associado a uma origem cultural/étnica/racial diferente, e um futuro desejado de inclusão e pertença europeia? Como é possível projectar uma identidade juvenil reivindicativa num cenário de exclusão social? É possível empoderar as identidades tradicional e historicamente desvalorizadas?

\section{Desafios conceptuais e metodológicos}

No intuito de responder a estas questões analisaremos os principais elementos que contribuem na formação das identidades dos jovens de origem imigrante. No entanto cabe reflectir até que ponto o facto de "ser jovem" é uma característica transversal aos jovens estudados, e se resulta possível dissociar a juventude do facto de serem imigrantes ou descendentes de imigrante? Ainda, ponderamos como são negociadas e construídas essas identidades nos diferentes contextos de estudo.

Neste caso, a utilização da perspectiva comparativa dupla, que considerou os jovens dos diferentes contextos de estudo e os jovens autóctones e descendentes, resultou enriquecedora porque permitiu identificar padrões comuns entre os jovens, bem como aspectos diferenciadores, que salientam a importância da análise conjunta dos diferentes contextos, permitindo comparar entre a duplicidade que implica ser jovens e de origem imigrante. Por outro lado, como toda comparação, esta perspectiva também apresenta desafios, particularmente nos aspectos relacionados às questões metodológicas, como, por exemplo, o próprio desenho do questionário para ser aplicado em diversos contextos com histórias de migração diferenciadas: com vínculos históricos e coloniais ou sem eles, envolvendo antigas ou novas migrações, com padrões de integração dissimiles. Ou também lidar com a aplicação a realidades que implicavam amostras nem sempre comparáveis, com a dificuldade acrescida da própria definição da categoria "jovem descendente de imigrante", devido à inexistência dum critério comum para definir esta variável entre os vários contextos de estudo.

Finalmente, como já afirmamos, um dos maiores desafios metodológicos enfrentados foi a denominação da categoria segunda geração de imigrantes: enquanto nos Estados Unidos e no mundo anglosaxónico é aceite de forma pacífica, em Europa continental não existe consenso sobre sua utilização. Se bem já manifestamos a nossa opinião sobre o assunto, durante o 
desenvolvimento do projecto de investigação foi necessário decidir sobre a terminologia a ser utilizada, sendo que cada equipa se pronunciou de acordo com a realidade identificada. Nos nove contextos de estudo concretos os casos identificados envolveram uma panóplia de situações que abrangeram desde uma verdadeira segunda geração nascida no país de residência dos pais, os jovens que chegaram com diferentes idades durante a infância ou adolescência, os jovens migrantes que acompanhavam os pais e ainda, mesmo que menos numerosos, os jovens que decidiram emigrar por decisão pessoal.

\section{Parte I - Metodologias e cenários: contextos locais e sócio- económicos}

O projeto decorreu num total de nove cidades, Barcelona, Berlim, Génova, Lisboa, Madrid, Metz, Porto, Roma e Utrecht localizadas em seis países da Europa Continental, Itália, França, Portugal, Alemanha, Espanha e Holanda. Foram utilizadas metodologias quantitativas (inquérito) e qualitativas (etnografias baseadas em observação participante, entrevistas em profundidade e analise de discurso). No entanto neste artigo só desenvolvemos a etnografia levada a cabo na Área Metropolitana de Lisboa.

A investigação quantitativa envolveu a realização dum inquérito por questionário que foi aplicado a jovens com idades compreendidas entre os 15 e $25^{9}$ anos, abrangendo os imigrantes/descendentes de imigrantes e os autóctones. Os jovens autóctones foram considerados como grupo de controlo, permitindo perceber as semelhanças e diferenças entre os grupos. Na maioria dos contextos, o inquérito foi realizado em escolas públicas localizadas nos bairros escolhidos pelo que a categorização autóctones e descendentes não foi premeditada. No entanto em alguns dos contextos, de modo a identificar jovens fora do sistema de ensino formal e mais velhos, também foi aplicado em associações civis, igrejas, universidades, ou no próprio bairro, nos locais de concentração dos jovens no espaço público. Assim, devemos reconhecer que a aplicação do inquérito nas escolas implica uma sobre-representação dos jovens dentro do sistema escolar. No entanto este enviesamento pode ser desculpado enquanto a escola é uma instituição fundamental na socialização e nas sociabilidades dos jovens com impacto no processo de formação das identidades. Apesar da grande maioria ser formada por alunos, em Madrid

9 A escolha do intervalo etário compreendido entre os 15-25 anos não foi pacífico. Mesmo os estudos recentes, não coincidem na definição etária, e alguns estudos prolongam a juventude até passados os 30 anos, devido a que muitos jovens ficam a viver com os pais até o casamento ou até atingir a indepedência económica, especialmente nos países do sul da Europa. No estudo qualitativo a questão etária foi flexibilizada considerando os círculos de sociabilidades dos jovens, pelo que abrangeu a alguns jovens mais velhos até os 30 anos inclusivamente. 
e Berlim foram incluídos também jovens inseridos no mercado de trabalho. No total foram aplicados um total de 4.738 inquéritos, cuja distribuição se encontra na Tabela 1, abrangendo autóctones e descendentes.

TABELA 1 - Distribuição da Amostra per contexto e grupo

\begin{tabular}{|l|c|c|c|c|c|}
\hline \multirow{2}{*}{ Cidade } & Total & \multicolumn{2}{|c|}{ Autóctones } & \multicolumn{2}{c|}{ Imigrantes } \\
\cline { 2 - 6 } & $\mathbf{N}$ & $\mathbf{N}$ & $\%$ & $\mathbf{N}$ & $\%$ \\
\hline Barcelona & 704 & 376 & 53,4 & 328 & 46,6 \\
\hline Berlim & 533 & 146 & 27,4 & 387 & 72,6 \\
\hline Génova & 598 & 300 & 50,2 & 298 & 49,8 \\
\hline Lisboa & 567 & 264 & 46,6 & 303 & 53,4 \\
\hline Madrid & 599 & 300 & 50,1 & 299 & 49,9 \\
\hline Metz & 603 & 304 & 50,4 & 299 & 49,6 \\
\hline Porto & 300 & 150 & 50,0 & 150 & 50,0 \\
\hline Roma & 600 & 306 & 51,0 & 294 & 49,0 \\
\hline Utrecth & 234 & 78 & 33,3 & 156 & 66,7 \\
\hline \multicolumn{1}{|c|}{ Total } & 4739 & 2224 & $46,9 \%$ & 2514 & 53,1 \\
\hline
\end{tabular}

Elaboração própria

A Tabela 2 sintetiza de forma esquemática características relevantes dos contextos estudados (principais comunidades migrantes, idade dos inquiridos e lugar de aplicação do inquérito), ilustrando algumas das semelhanças e diferenças entre as amostras. No questionário foram recolhidos dados demográficos (família, trabalho, educação e habitação) e informação sobre as esferas de sociabilidade, lazer, identidade, discriminação e expectativas em relação ao futuro, algumas das quais são analisadas no presente trabalho.

TABELA 2 - Contextos locais e amostras

\begin{tabular}{|l|l|}
\hline \multicolumn{1}{|c|}{ Cidade } & \multicolumn{1}{|c|}{ Características principais } \\
\hline Madrid (Espanha) & $\begin{array}{l}\text { Idade: 15-24 - Local: bairros - Origem maioritário: Equador, Marrocos, } \\
\text { Roménia, China }\end{array}$ \\
\hline Barcelona (Espanha) & $\begin{array}{l}\text { Idade: 15-24 - Local: escolas nos bairros escolhidos - Origem maioritário: } \\
\text { Equador, Rep. Dominicana, Bolívia, Peru }\end{array}$ \\
\hline Lisboa (Portugal) & $\begin{array}{l}\text { Idade: 15-24 - Local: escolas nos bairros escolhidos, associações - Origem } \\
\text { maioritário: Cabo Verde, Angola, Guiné Bissau }\end{array}$ \\
\hline Porto (Portugal) & $\begin{array}{l}\text { Idade: 15-24 - Local: escolas, igrejas, universidade, associações - Origem } \\
\text { maioritário: Cabo Verde, Angola, Ucrânia, China }\end{array}$ \\
\hline Génova (Itália) & Idade: 15-24 - Local: escolas - Origem maioritário: Equador, Albânia, Peru \\
\hline Roma (Itália) & $\begin{array}{l}\text { Idade: 15-24 - Local: escolas - Origem: Roménia, Equador, Peru, Moldávia, } \\
\text { China }\end{array}$ \\
\hline
\end{tabular}




\begin{tabular}{|l|l|}
\hline Berlim (Alemanha) & $\begin{array}{l}\text { Idade: 16-25 - Local: escolas nos bairros escolhidos - Origem maioritário: } \\
\text { Turquia }\end{array}$ \\
\hline Metz (França) & $\begin{array}{l}\text { Idade: 14-24 - Local: escolas nos bairros escolhidos - Origem maioritário } \\
\text { Algéria, Turquia, Marrocos }\end{array}$ \\
\hline Utrecht (Holanda) & Idade: 16-24 - Local: escolas - Origem: Marrocos e Turquia \\
\hline
\end{tabular}

Elaboração própria

Uma das principais diferenças identificadas foi a importância da presença relativa e a sua distribuição nos diferentes contextos dos jovens de origem imigrante nascidos já nos países europeus (a chamada segunda geração), ilustrando as diferentes histórias migratórias, como mencionado. Em termos gerais, a percentagem de jovens nascidos no país de destino dos pais permitiu uma clara distinção entre as cidades/países com uma tradição migratória assentada, as cidades/países de imigração mais recente e ainda as cidades/países com ambas as situações. Para os casos de Berlim, Metz e Utrecht a maioria dos jovens inquiridos pertence a uma segunda e inclusive terceira geração, enquanto para o caso de Barcelona, Madrid e Génova, a grande maioria nasceu fora do país de destino, tratando-se duma primeira geração de jovens e crianças, que chegaram em diferentes etapas das suas vidas. Lisboa, Porto e Roma conformam ainda uma realidade diferente, combinando uma imigração recente com outra de longa data, existindo percentagens semelhantes de jovens imigrantes recém-chegados e descendentes de imigrantes nascidos no país de destino dos pais, como indica a Tabela 3. O critério para ser considerado imigrante/descendente de imigrante incluía dois aspectos: o país de nascimento do jovem (origem ou destino) e o dos pais (se pelo menos um dos pais - pai ou mãe - tinha nascido num outro país).

\section{TABELA 3 - Antiga e recente imigração e percentagem de jovens de origem imigrante}

\begin{tabular}{|c|c|c|}
\hline $\begin{array}{c}\text { Nascidos no estrangeiro } \\
\text { (maioria) }\end{array}$ & Mista & $\begin{array}{c}\text { Nascidos no país considerado } \\
\text { (maioria) }\end{array}$ \\
\hline $\begin{array}{c}\text { Barcelona, Madrid e Génova } \\
>90 \%\end{array}$ & $\begin{array}{c}\text { Roma, Lisboa e Porto } \\
15-55 \%\end{array}$ & $\begin{array}{c}\text { Berlim, Metz e Utrecht } \\
>55 \%\end{array}$ \\
\hline
\end{tabular}

Elaboração própria

A origem dos imigrantes e dos seus descendentes é diversificada, em alguns casos resulta uma consequência das migrações pós-coloniais e noutras está vinculada à globalização e ao alargamento dos mercados de trabalhos, dificultando parcialmente a análise comparativa. Os grupos ou comunidades migrantes escolhidos respondem geralmente à importância relativa de 
cada uma, envolvendo geralmente as mais numerosas nos contextos locais analisados (Tabela 2).

A caracterização socio-demográfica dos jovens autóctones e dos descendentes sugere perfis diferenciados em algumas variáveis enquanto são mais homogéneo em outras. No nível de educação atingido, os pais (mães e pais) dos jovens autóctones têm, no geral, um maior grau de formação que os imigrantes. No entanto houve algumas excepções. As mães imigrantes em Roma, Barcelona, Porto e Génova apresentaram um nível elevado de educação ilustrando um estatuto socio-económico na origem que condiz com o nível de formação atingido, indicando também um processo de desqualificação após migração. No outro extremo, as mães imigrantes de origem turco, marroquino e africano representam proporções consideráveis entre as que não receberam educação formal ou tiveram acesso a uma formação básica, que se ajusta ao lugar ocupado no mercado de trabalho, no caso de estarem inseridas, especialmente as mulheres de origem africana em Portugal. Analisando o nível de formação dos pais, as diferenças entre uns e outros são menos evidentes que entre as mães. Relativamente à profissão, no geral os pais e as mães autóctones têm melhores ocupações que os imigrantes, já que estes desenvolvem maioritariamente trabalhos de pouca qualificação, mesmo aqueles imigrantes com mais educação. Os trabalhos mais comuns entre as mães imigrantes são as limpezas e na restauração enquanto entre os pais predomina a construção civil, sendo possível inferir uma brecha entre autóctones e imigrantes no estatuto sócio-económico, mesmo quando os filhos estudam nas mesmas escolas e moram em bairros nos arredores dessas escolas.

Entre os jovens, considerar o sucesso/insucesso escolar é uma variável fundamental ${ }^{10}$, porque a educação é considerada chave na mobilidade ascendente e um indicador do nível/grau de integração ${ }^{11}$. Neste sentido a amostra abrangida apresentou tendências consolidadas, os jovens autóctones tiveram um melhor desempenho escolar, repetindo menos vezes (Génova, Roma e Madrid) enquanto os descendentes de imigrantes apresentaram níveis mais elevados de fracasso e repetição (Barcelona, Berlim, Lisboa, Metz, Porto e Utrecht). De todos os jovens descendentes de imigrantes, os de Lisboa tiveram a taxa mais elevada de insucesso escolar, sendo que dos jovens inquiridos, um $71 \%$ tinha repetido pelo menos uma vez um ano de estudo, enquanto a taxa dos jovens autóctones atingia o 40\%. A performance dos jovens no sistema formal de ensino pode ter um papel importante nos

\footnotetext{
10 MELIA, op. cit.; PARELLA, op. cit.

11 MELIA, op. cit., p. 127.
} 
sentimentos de pertença e ajustamento à sociedade de acolhimento e no desenvolvimento das identidades juvenis.

\section{Principais aspectos da identidade de jovens descendentes de imigrantes: resultados duma analise quantitativa transnacional}

A adolescência representa "um momento de identidades em conflito em qualquer contexto, implica(ndo) ainda um grau maior de complexidades para os jovens nascidos no estrangeiro e os filhos dos imigrantes"12. Esta etapa de transição à vida adulta coincide com uma série de situações que envolvem a pertença e identificação com as culturas denominadas minoritárias das famílias e a cultura maioritária predominante da sociedade onde vivem, enquanto o resultado influenciará certamente as identidades que os jovens desenvolvam, acompanhando-os para a seguinte fase. Neste sentido devemos distinguir entre identidades e identificação como aspectos complementários mas diferenciados.

As identidades são individuais ou colectivas, implicando diferentes níveis de referência, mas ambas envolvem uma série de características e referenciais comuns (valores, comportamentos, visuais, etc.) entre aqueles que as partilham. No caso dos jovens, ambas são importantes, no entanto na juventude a pressão dos pares e a opinião dos amigos e colegas tendem a ser mais valorizadas, pelo que as identidades colectivas exercem maior influência nas identidades individuais (assumindo que são mais de uma, já que envolvem género, idade, classe social, etnicidade/raça, origem, etc.). Neste sentido, resulta útil considerar as identidades colectivas em três dimensões: a partilha de características comuns entre os membros de um determinado grupo, a auto-representação como entidade colectiva e a representação externa que outros fazem dos membros do grupo ${ }^{13}$, para assim reflectir sobre as características partilhadas pelos jovens, como se representam ou vêem a si próprios, e como são percebidos pelos outros. Consequentemente, o processo de formação das identidades envolve processos individuais e colectivos e ambos permitem uma melhor compreensão do fenómeno com um todo.

Neste trabalho a identidade foi analisada quer na auto-percepção, quer na sua percepção externa numa relação contínua e dialéctica, envolvendo variáveis como a idade, o género, o estilo de roupas, a origem, a cultura, a orientação sexual, a cor da pele e o estatuto socioeconómico. Assim, os resultados do inquérito europeu oferecem algumas pistas importantes sobre os

\footnotetext{
12 MELIA, op. cit., p. 127.

${ }^{13}$ COSTA, Antonio F. da. Sociedade de Bairro.
} 
aspectos mais relevantes na formação da identidade dos jovens autóctones e descendentes de imigrantes. Contudo somos conscientes do carácter dinâmico e histórico das identidades e reconhecemos as limitações deste tipo de analise.

A identidade é central para os jovens por envolver uma etapa de crescimento, mudanças e transformações a vários níveis, na qual emergem conflitos identitários relacionados com as pertenças múltiplas, as quais são negociadas com os pais, na escola, no bairro, na sociedade. Nos jovens imigrantes, além dos elementos comuns partilhados com os jovens em geral, ainda somam-se as pertenças relacionadas com o país de origem (deles e/ ou dos pais) que acrescentam mais camadas às identidades (para utilizar a metáfora de Soysal ${ }^{14}$ ) nas quais desenvolvem empatias diferentes em relação a certas pertenças.

O inquérito contemplou como identidades dos jovens as seguintes pertenças: i) a identidade geopolítica (Europeia, nacional, local e estrangeira); ii) a auto-identidade (como os jovens se definem a si mesmos); e iii) a identidade social (qual sua percepção sobre como os outros os consideram). Ainda foram analisados os espaços como fontes de identificação. Em relação à identidade geopolítica (Europeia, nacional, local e estrangeira), verificam-se algumas diferenças "esperadas": os jovens autóctones têm mais desenvolvida a identidade europeia, nacional e local, enquanto os jovens de origem imigrante referenciam mais a identidade estrangeira, com algumas singularidades, como em Lisboa, Metz e Roma, onde resultam significativas várias outras identidades como a local, a nacional e inclusivamente a europeia, aproximando os sentimentos de pertenças aos dos jovens autóctones. Esta situação pode estar relacionada com o tempo de estadia no país de destino, especialmente considerando que uma alta percentagem destes jovens nasceu no país de destino dos pais ou foram socializados nele. No entanto, também é possível que existam explicações "localizadas" muito vinculadas a processos particulares de certas cidades, como pode ser Berlim, onde os processos de integração pós queda do Muro de Berlim, somado a outros processos identitários específicos de certos bairros "guetizados" localmente, possam explicar a falta de afinidade como europeus, ou mesmo na Holanda, onde os jovens mesmo que nascidos no país são considerados alóctones (ou de origem estrangeira, perpetuando a estigmatização, sem conseguirem atingir nunca a categoria de autóctones). Estes casos ilustram uma dissociação da pertença a longo prazo.

Um outro aspecto inter-relacionado refere-se às intensidades das pertenças geopolíticas. Neste sentido observa-se que enquanto os jovens

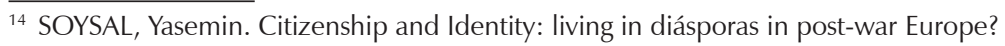


de origem imigrante de Lisboa apresentam uma intensidade forte na identificação local, os de Barcelona e Madrid, ambos recém-chegados, apresentam uma pertença muito mais fraca. Seguindo este raciocínio, os jovens que se sentem "mais estrangeiros" são em geral aqueles com períodos mais breves de residência, como Madrid, mas também os jovens imigrantes de Berlim que não se sentem acolhidos. O caso de Roma é interessante já que tantos os jovens autóctones como os descendentes manifestaram uma tendência à identidade estrangeira, sem podermos explicar se está associado a uma identidade cosmopolita ou algum outro factor. A Tabela 4 sintetiza os resultados relativos às identidades geopolíticas (que não abrangeram Porto e Génova devido ao modelo de inquérito aplicado localmente).

TABELA 4

Identificação Geopolítica - Jovens autóctones e de origem imigrante

\begin{tabular}{|c|c|c|c|c|}
\hline \multirow{2}{*}{} & \multicolumn{4}{|c|}{ Origem imigrante (escala de 0 a 5) } \\
\cline { 2 - 5 } & Europeia & Nacional & Local & Estrangeira \\
\hline Barcelona & 0,89 & 0,91 & 0,79 & 1,84 \\
\hline Lisboa & 3,18 & 1,75 & & 3,73 \\
\hline Madrid & 1,40 & 3,36 & 3,71 & 2,95 \\
\hline Metz & 2,90 & 1,20 & 1,50 & 3,90 \\
\hline Roma & 2,75 & 2,72 & 3,06 & 2,01 \\
\hline Utrecht & 2,07 & 2,65 & 2,42 & 3,84 \\
\hline \multirow{2}{*}{ Burly } & & 2,37 & 2,41 & 3,31 \\
\hline & Europeia & Nutóctones (escala de 0 a 5) & \\
\hline Barcelona & 1,99 & 1,28 & Local & Estrangeira \\
\hline Berlim & 3,50 & 3,94 & 1,74 & 0,23 \\
\hline Lisboa & 3,47 & 4,15 & 4,35 & 1,44 \\
\hline Madrid & 2,70 & 3,00 & 3,30 & 1,70 \\
\hline Metz & 3,48 & 4,13 & 2,97 & 0,43 \\
\hline Roma & 2,88 & 3,94 & 3,46 & 3,12 \\
\hline Utrecht & 2,76 & 4,08 & 2,41 & 0,24 \\
\hline
\end{tabular}

Elaboração própria

Com referência aos espaços de identificação, as categorias analisadas foram as seguintes: o bairro, a cidade, o país, o país de origem dos pais e Europa. Neste caso as diferenças entre os jovens autóctones e os de origem imigrante foram significativas. Enquanto os autóctones identificam-se mais com a cidade e o bairro, e em terceiro lugar com o país (percebido como um dado 
adquirido, embora relacionado com a construção da nação, tema que ultrapassa este trabalho), os jovens descendentes de imigrantes manifestaram uma maior empatia com o país de origem dos pais (reforçando a identidade estrangeira mencionada) seguida do bairro e a cidade (em qualquer caso identidades locais). No entanto, tantos os jovens autóctones como os de origem imigrante expressaram uma débil identificação com o contexto europeu. Para os jovens de origem imigrante, o país de residência mostrou ser mais relevante que Europa, mas em menor importância que as identidades estrangeira e local. Esta situação permite inferir que as identidades locais são muito relevantes para os jovens, e avançamos uma hipótese a ser explorada na etnografia desenvolvida em Lisboa: as identidades locais são centrais em termos de solidariedade e como geradoras de sentimentos de comunidade e pertença.

Considerando a auto-identidade, ou seja os aspectos que os jovens consideram importante na sua definição como tal, das variáveis incluídas no inquérito (idade, género, estilo de roupas, religião, origem, cultura, orientação sexual, cor da pele e estatuto socioeconómico), o género foi o aspecto mais salientado para todos/as os/as jovens, quer autóctones quer imigrantes. Em relação à segunda categoria houve diferenças entre os grupos, os autóctones indicaram a orientação sexual, quanto os descendentes de imigrantes optaram pela cultura/origem ou a religião no caso dos jovens muçulmanos (Metz, Utrecht e Berlim). Ainda, nos dois casos portugueses, os jovens de origem imigrante salientaram a cor da pele como parte da sua auto-identidade, Lisboa um 23\% e Porto um 13\%, tema que será abordado em profundidade no apartado etnográfico.

Em relação à identidade social vinculada à identificação externa, definida como a percepção dos jovens quanto à identificação que os outros fazem deles, observaram-se algumas diferenças entre os contextos. As características consideradas no inquérito foram, tal como no caso anterior, a idade, o género, o estilo de roupas, a religião, a origem, a cultura, a orientação sexual, a cor da pele e o estatuto socioeconómico. Na identificação externa, existem algumas diferenças significativas entre jovens autóctones e de origem imigrante. Os autóctones consideram que são definidos em base sobretudo à idade, seguido do género e o estilo de roupas, já os descendentes de imigrantes sentem que são definidos levando em consideração em primeiro lugar a origem (estrangeira) e num segundo plano, menos relevante, referem a idade, o estilo de roupas e o género; por outro lado estes jovens também apontaram algumas diferenças, dependendo dos contextos, por exemplo os jovens de origem imigrante aludiram a religião (em Utrecth e Berlim) e a cor da pele (Lisboa 
e Porto) como elementos distintivos para os outros. A Tabela 5 permite uma melhor apreciação das semelhanças e diferenças entre os grupos considerados.

TABELA 5 - Identificação Externa - Jovens autóctones e de origem imigrante

\begin{tabular}{|c|c|c|c|c|c|c|c|c|c|}
\hline & \multicolumn{9}{|c|}{ Origem imigrante } \\
\hline & Idade & Género & $\begin{array}{l}\text { Estilo } \\
\text { roupa }\end{array}$ & $\begin{array}{c}\text { Religi } \\
\text { ão }\end{array}$ & Origem & Cultura & $\begin{array}{l}\text { Orient. } \\
\text { Sexual }\end{array}$ & $\begin{array}{l}\text { Cor da } \\
\text { pele }\end{array}$ & $\begin{array}{l}\text { Socio- } \\
\text { econ. }\end{array}$ \\
\hline Barcelona & 23,6 & 10,1 & 19,2 & 1,5 & 27,8 & 6,1 & 2,0 & 8,1 & 1,6 \\
\hline Berlim & 18,0 & 10,6 & 13,0 & 10,2 & 31,3 & 2,5 & 2,5 & 1,8 & 3,2 \\
\hline Génova & 27,0 & 9,3 & 9,7 & 6,1 & 24,8 & 8,3 & 0,3 & 7,1 & 0,3 \\
\hline Lisboa & 23,8 & 18,4 & 16,3 & 2,9 & 13,8 & 9,2 & 1,3 & 13,0 & 1,3 \\
\hline Madrid & 12,5 & 1,0 & 14,1 & 6,4 & 43,8 & & & 2,4 & 1,0 \\
\hline Metz & 10,1 & 9,8 & 8,4 & 2,4 & 13,9 & 2,1 & & 1,0 & 2,1 \\
\hline Porto & 12,8 & 8,3 & 0,8 & 0,8 & 34,6 & 4,5 & & 14,3 & 3,8 \\
\hline Roma & 20,7 & 7,1 & 11,6 & 1,0 & 25,2 & 7,1 & 0,3 & 5,4 & 1,7 \\
\hline \multirow[t]{3}{*}{ Utrecht } & 60,0 & 49,3 & 58,7 & 49,4 & 56,0 & & & & \\
\hline & \multicolumn{9}{|c|}{ Autóctones } \\
\hline & Idade & Género & $\begin{array}{l}\text { Estilo } \\
\text { roupa }\end{array}$ & $\begin{array}{l}\text { Religi } \\
\text { ão }\end{array}$ & Origem & Cultura & $\begin{array}{l}\text { Orient. } \\
\text { Sexual }\end{array}$ & $\begin{array}{l}\text { Cor da } \\
\text { pele }\end{array}$ & $\begin{array}{l}\text { Socio- } \\
\text { econ. }\end{array}$ \\
\hline Barcelona & 39,2 & 19,5 & 24,6 & 0,7 & 3,9 & 4,7 & 3,0 & 2,5 & 1,9 \\
\hline Berlim & 29,4 & 29,4 & 16,5 & 0,9 & 2,8 & 0,9 & 4,6 & & 3,7 \\
\hline Génova & 35,0 & 12,3 & 25,7 & 0,7 & 5,3 & 3,3 & 1,0 & 1,0 & 1,7 \\
\hline Lisboa & 37,3 & 25,9 & 25,4 & 0 & 1,0 & 3,5 & 3,5 & 1,5 & 2,0 \\
\hline Madrid & 22,0 & 11,0 & 49,7 & 0,3 & 1,0 & & 1,3 & 1,3 & 0 \\
\hline Metz & 13,9 & 21,2 & 11,1 & 0,3 & 2,2 & 3,8 & & 0,6 & 1,6 \\
\hline Porto & 27,9 & 23,5 & 5,1 & 0,7 & 2,9 & 12,5 & 0,7 & 1,5 & 4,4 \\
\hline Roma & 28,8 & 14,7 & 16,3 & 1,3 & 2,0 & 9,2 & 1,6 & 2,0 & 1,0 \\
\hline Utrecht & 50,7 & 60,5 & 59,1 & 24,0 & 52,2 & & & & \\
\hline
\end{tabular}

Elaboração própria

\section{Discriminação}

A informação acima apresentada permite esboçar que a discriminação pode ajudar a explicar algumas das diferenças salientadas na construção das identidades juvenis. Como mencionado, a construção das identidades é um processo dinâmico e inacabado, onde os jovens desenvolvem afinidades múltiplas; este processo está sujeito a historicidades sendo influenciado pelas relações de poder existentes nas sociedades. Assim, as práticas de discriminação sofridas por estes sujeitos, quer por ser jovens, quer por ser imigrantes, quer 
pelo género ou pelo estilo de roupas, são aspectos importantes na configuração destas identidades. Neste sentido a discriminação e o racismo são factores relevantes neste processo e, segundo foi apontado por eles, tanto autóctones como imigrantes, estão presentes nas sociedades onde vivem. Em todos os contextos analisados, observa-se o reconhecimento duma elevada taxa de racismo, salvo no caso de Madrid onde 52\% manifesta que existe pouco racismo. Os percentagens maiores de percepção de racismo entre os jovens descendentes de imigrantes verificam-se em Berlin (43\%) e Metz (44\%), ambos contextos de imigração de longa data. A Tabela 6 sintetiza a percepção do racismo nos contextos estudados, nela resulta interessante observar como os jovens autóctones confirmam a existência do racismo nas sociedades europeias.

TABELA 6 - Percepção de racismo por parte dos jovens

\begin{tabular}{|c|c|c|c|c|c|c|c|}
\hline & \multicolumn{3}{|c|}{ Origem imigrante } & \multicolumn{4}{c|}{ Autóctones } \\
\hline & Nada & Pouco & Algum & Muito & Nada & Pouco & Algum \\
\hline Barcelona & 2,8 & 30,2 & 34,8 & 30,2 & 1,3 & 36,4 & 49,7 \\
\hline Berlim & 2,1 & 11,0 & 40,3 & 46,3 & 1,4 & 6,3 & 36,8 \\
\hline Génova & 3,0 & 21,3 & 49,0 & 25,3 & 3,3 & 11,3 & 49,7 \\
\hline Lisboa & 7,0 & 22,2 & 50,2 & 27,0 & 8,0 & 17,4 & 57,6 \\
\hline Madrid & 8,0 & 51,8 & 29,8 & 10,4 & 3,3 & 17,3 & 50,7 \\
\hline Metz & 5,2 & 7,3 & 38,7 & 44,3 & 4,4 & 7,9 & 39,6 \\
\hline Porto & 11,3 & 31,0 & 40,8 & 16,9 & 1,4 & 17,7 & 65,3 \\
\hline Roma & 0,7 & 13,6 & 53,4 & 31,6 & 1,3 & 11,4 & 48,0 \\
\hline Utrecht & 13,5 & 9,5 & 44,6 & 32,4 & 8,5 & 9,9 & 31,0 \\
\hline
\end{tabular}

Elaboração própria

Quando questionados sobre os motivos de discriminação, as respostas dos jovens varia significativamente segundo a origem, ou seja os autóctones e os descendentes imigrantes oferecem diferentes explicações. Enquanto os jovens autóctones assinalam a idade e o estilo de roupas como factores que explicam a discriminação, os jovens de origem imigrante apontam a origem, complementada com cultura, cor da pele e religião, dependendo do contexto local. Para o caso de Portugal (Lisboa e Porto) a razão mais importante de discriminação é a cor da pele; em Utrecht, a religião. Resumindo, a origem é importante em Barcelona (42\%), Berlin (75\%), Génova (42\%), Lisboa (22\%), Madrid (62\%), Metz (27\%), Roma (55\%) e Utrecht (31\%); a religião em Berlin (59\%), Metz (20\%), Porto (31\%) e Utrecht (56\%); a cor da pele em Lisboa (51\%) e Porto (36\%) e a cultura em Berlin (33\%) e Madrid (24\%). 
Analisando as respostas sobre os lugares onde os jovens sentem a discriminação, a escola apresenta-se como o espaço onde esta acontece mais frequentemente para todos os jovens, sem importar a sua origem, situação importante de ser analisada por ser o espaço no qual os jovens passam a maior parte do seu tempo, e onde interagem com professores e colegas. Um segundo espaço onde a discriminação é sofrida são os transportes públicos, no entanto esta discriminação é muito mais elevada no caso dos descendentes de imigrantes e não se verifica em Metz e Madrid. Neste último contexto o lugar de trabalho surge como um espaço de discriminação importante para os jovens, já que a idade média dos jovens entrevistados era mais elevada, estando muitos deles inseridos na esfera laboral. A Tabela 7 apresenta um resumo dos lugares onde os jovens experimentam maior discriminação em cada contexto estudado.

TABELA 7 - Espaços onde a discriminação juvenil acontece

\begin{tabular}{|l|c|c|}
\hline & Jovens de origem imigrante & Autóctones \\
\hline Lojas/Bares & Lisboa, Metz*, Utrecht & Barcelona*, Madrid, Utrecht \\
\hline Escola & $\begin{array}{c}\text { Barcelona, Berlim, Génova, } \\
\text { Madrid, Metz, Porto, Roma }\end{array}$ & $\begin{array}{c}\text { Barcelona, Berlim, Génova, Lisboa*, } \\
\text { Madrid, Metz*, Porto*, Roma, Utrecht }\end{array}$ \\
\hline Trabalho & Madrid & Madrid, Utrecht \\
\hline Bairro & Utrecht, Madrid & Lisboa*, Metz*, Roma \\
\hline Hospitais & Madrid* & Madrid* \\
\hline Transporte público & $\begin{array}{c}\text { Barcelona, Berlim, Génova, } \\
\text { Lisboa, Porto, Roma }\end{array}$ & Berlin, Génova*, Madrid, Porto* \\
\hline Instituições públicas & Berlim, Madrid & Berlim, Madrid \\
\hline Bancos & & Madrid \\
\hline
\end{tabular}

Casos seleccionados com mais do $20 \%(*)$, outros casos com percentagens menores a $20 \%$, mas considerados relevantes em termos comparativos

Este panorama geral sobre os jovens, as identidades e identificações no contexto europeu permitiu salientar algumas tendências. Uma se refere a algumas semelhanças nos processos de formação das identidades entre os jovens de todos as origens (como a idade e o género, incluso o estilo de roupas). No entanto ficou esclarecido que a influência de factores externos modela as identidades de formas diferentes, e que os descendentes de imigrantes acabam por herdar alguns marcadores diferenciadores como a origem, a cultura, a cor da pele e a religião. Estas primeiras conclusões indicam que é importante aprofundar como este processo decorre nos jovens descendentes de imigrantes, meninos e meninas, onde os processos de socialização modelam os futuros jovens europeus. 


\section{Parte II - Processos identitários racializados: etnografia juvenil}

Como já foi realçado, o conceito de identidade tem sido analisado e abordado desde diferentes perspectivas, quer sociológicas, antropológicas e psicológicas. Optamos por recorrer ao conceito de identidades em plural devido a que assumimos que os jovens desenvolvem/adoptam um conjunto delas de forma simultânea e super-postas. Nesta secção desenvolvemos o caso particular dos jovens residentes na Área Metropolitana de Lisboa, recorrendo ao trabalho etnográfico desenvolvido no marco do mesmo projeto europeu com jovens de origem imigrante, aprofundando alguns aspectos mais amplos vinculados às suas identidades.

A etnografia baseia-se numa combinação de métodos e técnicas qualitativas de observação participante, entrevistas semi-estruturadas com informantes chaves e entrevistas em profundidade com os jovens, recorrendo também à análise de discurso das "líricas" produzidas pelos jovens durante as atividades, e da carta aos políticos escrita também por eles para a conferência final do projecto. O trabalho de campo etnográfico decorreu num bairro da margem sul que integra a Área Metropolitana de Lisboa, e foi desenvolvido principalmente durante as atividades de verão dos jovens, incluindo tanto as tarefas de planeamento como a realização das mesmas. As atividades em causa foram seleccionadas livremente pelos jovens, e incluíram workshops de dança, graffiti, lírica, produção de música e produção de vídeo, e no fim realizou-se uma Festa Multicultural com a participação das diferentes entidades do bairro. As observações centraram-se nas interações dos participantes nos vários grupos, focando as relações entre meninas e meninos, entre os jovens das diferentes idades e origens (de origem cabo-verdiana, angolana, são-tomense, guineenses, e mistas), a interação com os monitores e organizadores das atividades, contemplando ainda os comportamentos e atitudes, os estilos de roupas e as atitudes refletidas.

No total foram realizadas 21 entrevistas a jovens entre 15 e 25 anos, 13 do sexo feminino e 8 masculino, todos de origem africana, alguns com nacionalidade portuguesa. As entrevistas em profundidade abarcaram uma ampla gama de questões, desde aspectos demográficos até questões pessoais, trajetórias residenciais, escolares e familiares dos jovens, opiniões e sentimentos sobre o bairro, a escola, as associações, as afiliações e pertenças, as experiências de discriminação, as esferas de sociabilidades, as expectativas de futuro e interesses. Neste artigo focamos apenas alguns dos aspectos relacionados com as identidade e a identificação dos jovens, tentando abordar que aspectos são centrais para estes jovens na conformação das suas identidades. 
Os dados qualitativos recolhidos confirmam os resultados quantitativos apresentados, sugerindo a idade e o género como aspectos centrais das identidades juvenis, em conjunção com a origem e a cultura (estas variáveis resultaram difíceis de separar, sendo que estavam relacionadas com a cultura e país de origem da família). O estilo de roupa também foi um aspecto importante, embora muito diferenciados dependendo do género. A modo de exemplo, em referencia ao estilo de roupas, as jovens identificaram-se com um estilo muito girly-like, feminino, cuidadoso, limpinho, mostrando uma atitude de conformidade, enquanto os rapazes adoptaram um estilo hip-hop/rapper, mais agressivo e contestatário, não por isso menos cuidado e produzido, que responde à estigmatização à qual os jovens negros estão sujeitos por parte da sociedade, sendo associados com a criminalidade, a marginalidade e a violência. Outras diferenças de género foram detectadas nos comportamentos de controlo, já que as meninas eram mais monitorizadas de perto pelas famílias, não podendo passar muito tempo nos espaços públicos, enquanto os rapazes tinham ampla liberdade para estar na rua e chegar tarde a casa, pois não precisavam assumir papeis domésticos como as meninas, que mesmo a terna idade eram obrigadas a tomar contas dos irmãos mais novos e sendo ainda responsáveis da realização de tarefas domésticas.

Por outro lado, a construção das identidades dos jovens descendentes de imigrantes apresenta consequentemente uma multiplicidade de referências identitárias que inclui elementos da cultura maioritária portuguesa e das várias culturas minoritárias de origem africano ou quadros de referência cultural de oposição ${ }^{15}$, transitando num contínuo identitário entre uma identificação portuguesa e uma africana ${ }^{16}$. Neste sentido reafirmam uma identidade híbrida que reforça sentimentos duma pertença mista ancorada em mais de uma cultura, que deve ser analisada também como um processo ideológico e político num contexto de pós-colonialismo no qual o racismo e a discriminação ganham um sentido específico vinculado à racialização.

É possível nestes jovens reconhecer alguns marcadores comuns que iremos aprofundar. O primeiro deles relaciona-se com a racialização da identidade, particularmente relacionada com o passado colonial, a construção colonial da identidade étnica e da lusofonia, que permite ressaltar a relação

${ }^{15}$ OGBU, John. The next generation: An ethnography of education in an urban neighborhood; IDEM. Minority education and caste: The American system in cross-cultural perspective; SEABRA, Teresa. Desigualdades de desempenho escolar: etnicidade, género e condição social em escolas básicas da Área Metropolitana de Lisboa.

16 PADILLA, Beatriz. Recriando identidades juvenis entre jovens de descendência Africana na Area Metropolitana de Lisboa; PADILLA, Beatriz e PALMA, Filipa. O racismo na "pele" dos jovens negros em Portugal; ORTIZ, op. cit. 
entre identidade e alteridade ${ }^{17}$ no reconhecimento duma posição discursiva dominante sobre o "outro-imigrante-jovem". O segundo refere à importância dum aspecto transcultural na identidade destes jovens, particularmente na procura duma pertença que transcenda a identificação estigmatizada e negativa à qual são sujeitos, tornando-lha um consumo cultural de padrões geracionais mais alargados e valorizados. Estes marcadores identitários, longe de ser exaustivos, sugerem identidades fragmentadas, negociadas continuamente ou em formação, identidades em tensão, geridas em vários frentes, identidades desempoderadas que lutam pelo reconhecimento e empoderamento.

\section{A racialização da etnicidade como factor explicativo}

A etnicidade e a raça, que são conjugadas de diferentes formas nos vários contextos, desempenhando um papel fundamental na formação das identidades de grupo ${ }^{18}$. A identidade étnica se configura em relação ao poder ou a falta de acesso ao mesmo, e nas sociedades hierarquizadas ${ }^{19}$, como a portuguesa, o não-poder por parte das culturas étnicas minoritárias as vezes é equiparável à racialização. A racialização é entendida como os processos ou situações culturais e políticas nas quais a raça é usada como explicação ou como um elemento de entendimento comum ${ }^{20}$, atribuindo significado aos comportamentos discriminatórios justificados em atributos culturais mais do que biológicos, também conhecido como novo racismo ou racismo cultural $^{21}$. Por outro lado, mesmo que a etnicidade seja entendida como a partilha das mesmas características e padrões culturais que os distinguem de outros grupos, a demarcação duma fronteira real e simbólica entre o étnico e o racial nem sempre resulta claro e observável para a cultura maioritária (portuguesa), que acaba por amalgamar numa única cultura africana-negra as especificidades étnicas próprias das culturas dos países de origem das famílias dos jovens envolvidos e a eles próprios. Para a cultura maioritária os jovens são jovens "negros" e serem de origem cabo-verdiana, angolana, são-tomense é um detalhe que não distinguem, pelo menos ao manifestarem os comportamentos e comentários racistas.

Assim, a racialização faz parte da identidade destes jovens, ilustrando como a sociedade na que vivem não os aceita como "portugueses". Os

\footnotetext{
17 PADILLA, op. cit.; MACHADO, Igor. Brazilian immigration and the reconstruction of racial hierarchies of the Portuguese empire.

${ }^{18}$ PADILLA, op. cit.; WIMMER, Andreas. Does ethnicity matter? Everyday group formation in three Swiss immigrant neighbourhoods; NAYAK, Anoop. After race: Ethnography, race and post-race theory.

${ }^{19}$ MACHADO, op. cit.

${ }^{20}$ Murji \& Solomons citado por WINDLE, Joel. The racialisation of African Youth in Australia.

${ }^{21}$ BARKER, Martin. The new racism: Conservatives and the ideology of the tribe.
} 
depoimentos assim o sugerem: "somos mais africanos em Lisboa que em África!"; "no autocarro ninguém se sinta ao meu lado"; "quando as senhoras (brancas) passam perto de mim, asseguram as malas como se eu fosse rouba-las"; "os policias me mandam parar sem motivos que o justifique", entre outros. Consequentemente os jovens de origem imigrante ao serem "singularizados racialmente" (racial profiling) negociam a sua auto-identidade (idade, género, origem, identificada com elementos positivos), com a identidade social (que inclui os vários elementos percebidos como negativos pelos outros membros da sociedade), e desta negociação resulta um processo de alterização, no qual os jovens são associados a um determinado grupo (minoritário) e dissociado de outro (maioritário); sendo que o grupo minoritário (negro) é relacionado a comportamentos desviantes e marginais, enquanto o grupo maioritário (portugueses brancos) é considerado desejáveis.

A pesar da alterização, os jovens contradizem a estigmatização reconhecendo de forma positiva as semelhanças identificadas, assumindo assim uma consciência comum na qual alguns elementos resultam seleccionados tendo a potencialidade de se tornarem uma característica de união. Como afirmou Saint-Maurice, "por um lado, implica que haja afinidades entre os membros do grupo, sejam elas reais ou simbólicas, e, por outro lado, que o grupo se defina em função de um referente, de um "outro", num contexto de interacção" ${ }^{\prime 22}$. Os jovens na tentativa de convergir à volta de algum marcador, escolheram o bairro como elemento unificador, mesmo sabendo-o que conta com má fama exterior, atribuindo-lhe uma valorização como símbolo de união. Em consequência, o "Vale da Amoreira" ganha um outro sentido, que pode ser comprovado na letra da canção composta pelos jovens durante as actividades de verão, que ilustra uma realidade crua com os problemas quotidianos do bairro mas resgata aspectos positivos vinculado aos afectos. A lírica foi escrita à múltiplas mãos, e cada jovem foi autor de uma estrofe, escolhendo a temática e língua. Transcrevemos a seguir a introdução, o refrão e uma estrofe.

\section{Vale da Amoreira (VA)}

\section{Introdução}

Tempo ka ta pára, ou seja ta dispara ka bo perdi tempo, VA na movimento

\section{REFRÃO}

O, O Vale da Amoreira, O nosso habitat Novos sonhos encontrar ah ah

\footnotetext{
${ }^{22}$ SAINT-MAURICE, Ana de. Identidades Reconstruídas: Cabo-verdianos em Portugal, p. 12.
} 
Só, Só mais uma barreira, Todos têm de acreditar É possível mudar ah ah

\section{(FÁBIO)}

Esta é a vida da nossa gente da rua /

onde a realidade atua mas a esperança continua

muitos com o objectivo de melhorar a vida /

envolvendo-se nas drogas no fumo e na bebida

V.A Vale da Amoreira nosso bairro de valor /

onde existe desemprego drama ao seu redor

O sitio onde aprendemos crescemos e vivemos / onde existem recordações (Boy) que não esqueceremos

A posição de alteridade a qual os jovens estão sujeitos se traduz numa posição discursiva específica sobre ser jovens descendentes de imigrantes africanos, reproduzindo significados e reificando algumas categorias hegemónicas relacionadas particularmente com a exclusão e com a ameaça. Neste sentido, os jovens constituem uma forma de contestação social e política na qual a etnicidade relacionada com a racialização, torna-se em modos de resistência à exclusão e ao racismo, adoptando um posicionamento que procura o empoderamento. Um fragmento da carta escrita pelos jovens do Vale da Amoreira para ser entregue aos políticos locais, nacionais e europeus, referia:

(....) O Vale da Amoreira é considerado por nós, os seus habitantes, a África em Portugal, onde as pessoas, em alguns aspectos, são mais calorosas, mais amigas e mais unidas. Há uns anos atrás era quase um lugar perfeito para qualquer negro que viesse de África porque assim nem sentiria muita diferença. Todavia, hoje o Vale da Amoreira, é um "povo" dividido em grupos, com grandes lutas físicas e graves problemas sociais. (....) A nossa cor é o maior entrave nas nossas vidas, mas isto é ainda pior para aqueles que são negros e portugueses porque são excluídos socialmente. Se somos tão postos de fora, que outra solução temos? Como forma de nos livrarmos das nossas frustrações, muitos de nós preferem seguir o caminho do sexo e da marginalidade, visto que não temos nada a perder.

Somos negros? Sim!

Somos imigrantes? Sim!

Somos negros portugueses? Sim!

Somos pessoas como outras quaisquer? Sim!

Então, porque é que somos tão excluídos? Deixem-nos mostrar um pouco da nossa realidade, da nossa cultura, das nossas capacidades, como trabalhadores, amigos, doutores, cidadãos ... e como PESSOAS. Deixem-nos mostrar que, mesmo crescendo num bairro crítico, valemos a pena! Valemos o esforço! Lutem 
por nós, lutem connosco! Lutem pelo nosso futuro e o futuro do país e até mesmo, por um mundo melhor! (....)

\section{O transcultural como identidade projetiva traslocal}

Um outro aspecto importante nas identidades são os padrões e consumos culturais juvenis. Estes padrões culturais podem ser nacionais, internacionais, transnacionais e/ou transculturais que podem ser recriados ou modelados de acordo às práticas locais nas que decorrem os processos de formação das identidades.

Como temos vindo a analisar, estes processos de formação das identidades são ambíguos por invocar uma origem no passado, que continua no presente, mas que simultaneamente acrescenta outras pertenças dos fluxos da cultura global ${ }^{23}$. Assim os símbolos identitários dos jovens são um produto da coexistência dinâmica de elementos da origem (nostalgia e memórias familiares) da sociedade de destino (vida quotidiana) e da cultura global (símbolos culturais globalizados e massificados muitas vezes vinculados a estilos e filosofias de vida).

Um exemplo deste processo é a crioulização ou hibridação da linguagem e a homogeneização da cultura africana em contraposição com as culturas étnico-nacionais como a guineense, a cabo-verdiana, a angolana, a são-tomense, a guineense, entre as principais, que são dois processos diferentes mas complementários ${ }^{24}$. Por um lado, os jovens optam por usar o crioulo duma forma renovada e inovadora (língua falada em Cabo Verde, e não dos outros crioulos de outros países africanos) recorrendo a ela como se fosse "calão" ou "gíria", muito diferente ao crioulo cabo-verdiano usado pelos adultos do bairro. A nova gíria juvenil inclui palavras em crioulo, termos angolanos, jargão tradicional dos jovens, palavras inventadas e resultantes de misturas de expressões típicas portuguesas, e de outras línguas provenientes de outras regiões do mundo, especialmente do inglês dos negros americanos envolvidos nos movimentos de contestação e resistência. Assim a ideia de cultura ${ }^{25}$ destes jovens relaciona-se com as raízes e herança cultural proveniente dos países africanos dos seus pais e familiares, mas que resulta em uma forma e prática cultural miscigenada que integra elementos africanos, portugueses, da cultura negra e do hip-hop quer nas preferências alimentares (comidas e bebidas), musicais e dos consumos ${ }^{26}$.

\footnotetext{
${ }^{23}$ HALL, Stuart. Cultural Identity and Diaspora; SOYSAL, op. cit.

24 PADILLA, op. cit.

${ }^{25}$ HEAVEN, Cara e TUBRIDY, Matthew. Global youth culture and youth identity.

${ }^{26}$ PADILLA, op. cit.
} 
Por outro lado, a visão étnicizada (nacionalistas) das culturas africanas aos olhos dos pais e familiares que focam a cultura cabo-verdiana, angolana, guineense, são-tomense (mesmo que exista diversidade dentro de cada uma) é homogeneizada ou ensamblada por parte dos jovens, tornando-Iha uma cultura juvenil referida como africana que incorpora os elementos mais valorizados e salientes de cada uma das culturas mencionadas, resultando numa miscigenação pan-africana. Esta tendência pode ser verificada nos consumos musicais e estilos de roupa, como se ilustra a seguir.

O gosto musical dos jovens de origem imigrante (africana) abrange os ritmos tradicionais como o kizomba, o funana e o kuduro até o rap cantado em crioulo e a cultura do Hip-Hop. O rap simboliza para estes jovens mais do que uma simples identificação musical, representando uma "cultura de resistência", um modo de vida, que Ihes permite assumir papéis mais activos e de maior envolvimento ${ }^{27}$, e estabelecer ligações com outros jovens, dentro e fora das fronteiras do bairro e raciais, no entanto também pode assumir riscos associados à proximidade a uma cultura de marginalização. Por outro lado, o estilo de roupa representa uma trademark dos jovens devido à importância da imagem para os jovens e a sua auto-estima. O estilo mais destacado está vinculado ao hip-hop nos rapazes, que vestem grandes camisolas, calças baixas, bonés e ténis de marca, mostrando claramente uma tendência global, mas ao mesmo tempo a escolhas das cores, os símbolos e os acessórios africanos, localizam a vestimenta tornando-a translocal, ou seja, como afirmam, adoptando uma posição de agência empoderadora ${ }^{28}$.

\section{Conclusões}

O presente e especialmente o futuro de Europa pode estar comprometido. Tal afirmação resulta da analise dos dados quantitativos e qualitativos, expostos neste artigo, que ilustrou o gap existente entre os jovens autóctones e os de origem imigrante em relação aos processos e resultados de formação das identidades. Isto sugere que se medidas a curto, mediano e longo prazo não são introduzidas nos diferentes países europeus tendentes a melhorar a inclusão dos jovens, especialmente de aqueles de origem imigrante, o futuro não é promissório.

Como vimos, os processos de formação das identidades dos jovens autóctones e de origem imigrante são mais semelhantes no que diz respeito a auto-identificação que quando se considera a identificação externa, ilustrando como o preconceito, a discriminação e o racismo modelam as

\footnotetext{
27 PADILLA, op. cit.

${ }^{28}$ BRICKELL, Katherine; DATTA Ayona. Translocal Geographies: Spaces, Places, Connections.
} 
identidades, contribuindo negativamente neste processo. A discriminação é vivida mais de perto em instituições sociais como a escola, cujo objectivo além da educação formal é a socialização das crianças e jovens para facilitar a adaptação à sociedade local, nacional e internacional. Pelos vistos, o insucesso desta instituição deve ser debatido amplamente, consultando todos os interessados, tentando identificar os factores que tem contribuído para estes resultados, e delimitando responsabilidades. A discriminação é sentida também pelos jovens nos espaços públicos e em outras instituições públicas, o que sugere a necessidade de pensar instrumentos de combate aos comportamentos discriminatórios tanto a nível europeu como locais, que compensem as injustiças identificadas. Contudo, o racismo ainda atravessa as sociedades europeias, favorecendo os grupos maioritários e prejudicando os minoritários, situação que no fim deteriora a qualidade de vida global dos cidadãos e cidadãs.

A aproximação qualitativa corroborou que a racialização das identidades juvenis no caso dos jovens de origem imigrante é um aspecto que influencia negativamente a vida destes jovens, pelo que todas as medidas conducentes a pôr um ponto final aos processos de racialização deveria ser uma prioridade nas políticas públicas quer de imigração e integração, quer nas políticas para a juventude e de igualdade, tendendo a focar a mudança de comportamento das próximas gerações. Neste sentido, não há melhor fecho para este artigo que honrar as próprias palavras dos jovens do Vale da Amoreira...

Nós não somos uma cor ... somos Portugal e se apostarem em nós, também estarão a apostar em Portugal. Não olhem para nós como o lado negro de Portugal, mas sim como o futuro de Portugal. Um futuro que precisa de ajuda, precisa de ser ensinado, precisa de ser olhado e precisa de novos modelos.

\section{Bibliografia}

APARICIO, Rosa; TORNOS, Andrés. Hijos de inmigrantes que se hacen adultos: marroquíes, dominicanos y peruanos. Madrid: Ministerio de Trabajo y Asuntos Sociales, 2006.

BARKER, Martin. The new racism: Conservatives and the ideology of the tribe. London: Junction Books, 1981.

BOLZMAN, Cláudio; FIBBI, Rosita; VIAL, Marie. Secondas - Secondos. Le processus $d^{\prime}$ integration des jeunes adultes issus de l'immigration espagnole et italienne en Suisse. Zürich: Seismo, 2003.

CASAS, Monserrat (ed.). També catalans: fills i filles de famílies immigrades. Barcelona: Fundació Jaume Bofill, 2003. 
BRICKELL, Katherine; DATTA Ayona. Translocal Geographies: Spaces, Places, Connections. Burlington: Ashgate, 2011, p. 261-266.

COLOMBO, Enzo; LEONINI, Luisa; REBUGHINI, Paola. Different But Not Stranger: Everyday Collective Identifications among Adolescent Children of Immigrants in Italy. Journal of Ethnic and Migration Studies, v. 35, n. 1, 2009, p. 37-59.

COSTA, Antonio F. da. Sociedade de Bairro. Oeiras: Celta, 2000.

CRUL, Maurice; SCHNEIDER, Jens; LESLIE, Frans. The European Second Generation Compared. Does the Integration Context Matter? Amsterdam: Amsterdam University Press, 2012.

ESSOMBA, Miguel Angel et alii. Immigrant adolescents in Catalonia and the construction of cultural identity: Life stories and inclusion processes. In ROSS, Alistair; CUNNINGHAM, Peter (eds.). Reflecting on Identities: Research, Practice and Innovation. London: CiCe, 2008, p. 579-594.

GUALDA, Estrella. Segunda Generación y adolescents y jóvenes inmigrantes: el caso de Huelva. In GUALDA, Estrella; RODRIGUES Iván. Infancia y juventud en las migraciones internacionales. Perspectivas globales y locales. Madrid: Ed. Exilibris ediciones, 2007.

HALL, Stuart. Cultural Identity and Diaspora. In BRAZIEL, Jana Evans; MANNUR, Anita (eds.). Theorizind Diaspora. Malden, MA: Blackwell, 2003, p. 233-246.

HEAVEN, Cara; TUBRIDY, Matthew. Global youth culture and youth identity. In Highly Affected, Rarely Considered: IYP Youth Commission into Globalisation Report. Surry Hills: Oxfam International Youth Parliament (OIYP) Oxfam Community Aid Abroad, 2002.

KOEFOED, Lasse; SIMONSEN, Kirsten. Rescaling identities: Embodied others and alternative spaces of identification. Ethnicities, v. 12, n. 5, 2012, p. 623-642.

MACHADO, Fernando, MATIAS, Raquel. Descendentes de Imigrantes nas Sociedades de Acolhimento: Linhas de Identificação Sociológica. CIES e-Working Paper N. 13/2006, Lisboa, 2006.

MACHADO, Igor. Brazilian immigration and the reconstruction of racial hierarchies of the Portuguese empire. Vibrant Virtual Brazilian Anthropology, v. 1, 2004, p. 1-22.

MELIA, Michael. Transatlantic Dialogue on Integration of Immigrant Children and Adolescents. International Migration, v. 42, n. 4, 2004, p. 123-139.

NAYAK, Anoop. After race: Ethnography, race and post-race theory. Ethnic and Racial Studies, v. 29, n. 3, 2006, p. 411-430.

OGBU, John. The next generation: An ethnography of education in an urban neighborhood. New York: Academic, 1974.

. Minority education and caste: The American system in cross-cultural perspective. New York: Academic, 1978.

ORTIZ, Alejandra. Identidades, pertenças e afinidades dos jovens descendentes de imigrantes africanos na Área Metropolitana de Lisboa. Migrações, n. 11, 2013, p. 157-184.

PADILLA, Beatriz. Recriando identidades juvenis entre jovens de descendência Africana 
na Area Metropolitana de Lisboa. In PAIS, José Machado; BENDIT, René; FERREIRA, V. Sérgio (orgs.). Jovens e Rumos. Lisboa: Imprensa de Ciências Sociais, 2012, p. 159-180. PADILLA, Beatriz; ORTIZ, Alejandra. Final local report on questionnaire analysis. EU Project TRESEGY, Sixth Framework Programme, 2008.

PADILLA, Beatriz; RODRIGUES, Vera; ORTIZ, Alejandra. Monographic Report on Ethnographic Data. EU Project TRESEGY. Sixth Framework Programme, 2008.

PADILLA, Beatriz; PALMA, Filipa. O racismo na "pele" dos jovens negros em Portugal. In MARTINS, Rosana; PEDROSO, Maria Goreti (orgs.). Espaço Público, Direitos Humanos \& Multimédia: Novos Desafios. Rio de Janeiro: Editora Multifoco, 2011. PARELLA, Sónia. Desigualdades de Género. Jóvenes Inmigrantes. (Tomo 5) Informe 2008 Juventud en España. Madrid: Observatório de la Juventude en España, 2008.

PORTES, Alejandro (ed.). The New Second Generation. New York: Russell Sage Foundation, 1996.

PORTES, Alejandro; RUMBAUT, Rubén (eds.). Legacies: The Story of the Immigrant Second Generation. Berkeley: University of California Press, 2001.

PORTES, Alejandro; FERNANDEZ-KELLY, Patricia; HALLER, William. La asimilación segmentada sobre el terreno: la nueva segunda generación al inicio de la vida adulta. Migraciones, v. 19, 2005, p. 7-58.

ROTH, Jodie; BROOKS-GUNN, Jeanne. What do adolescents need for healthy development? Implications for youth. Social Policy Report. Giving Child and Youth Development Knowledge Away, v. XIV, n. 1, 2000, p. 3-19.

SAINT-MAURICE, Ana de. Identidades Reconstruídas: Cabo-verdianos em Portugal. Oeiras: Celta Editora, 1997.

SEABRA, Teresa. Desigualdades de desempenho escolar: etnicidade, género e condição social em escolas básicas da Área Metropolitana de Lisboa. Sociologia, Número temático: Imigração, Diversidade e Convivência Cultural, 2012, p. 185-210.

SOYSAL, Yasemin. Citizenship and Identity: living in diásporas in post-war Europe? Ethnic and Racial Studies, v. 23, n. 1, 2000, p. 1-15.

WINDLE, Joel. The racialisation of African Youth in Australia. Social Identities, v. 14, n. 5, 2008, p. 553-566.

WIMMER, Andreas. Does ethnicity matter? Everyday group formation in three Swiss immigrant neighbourhoods. Ethnic and Racial Studies, v. 27, n. 1, 2004, p. 1-36.

\section{Abstract}

\section{Construction of the identities of young people of immigrant origin in Europe: results from an European Project}

This article describes and analyzes some of the factors that influence the construction of identities of young people in Europe of immigrant origin. The results derive from a European research project entitled "Towards the social construction of a European youth: the experience of inclusion and exclusion in the public sphere of young second-generation migrants" [1] 
developed between 2006 and 2009 in nine cities across five countries: Spain (Madrid and Barcelona), Italy (Genoa and Rome), Portugal (Lisbon and Porto), France (Metz), Germany (Berlin) and the Netherlands (Utrecht). The first part analyzed the quantitative data collected in the study contexts, comparing the young descendants of immigrants with the native youth, and focuses on the issue of identity as a central subject in the inclusion process of young immigrants. The second part discusses some of the identity markers present in young children of immigrants in Portugal, using ethnographic data collected specifically for the case of young people in the Lisbon Metropolitan Area that focuses on issues of identity, gender and discrimination.

Keywords: immigrant origin, descendants of immigrants, youth identities, Portugal, Europe.

Recebido para publicação em 12/02/2014.

Aceito para publicação em 08/05/2014.

Received for publication on February, 12 2014.

Accepted for publication on May, 08 $8^{\text {th }}, 2014$.

ISSN impresso: 1980-8585

ISSN eletrônico: 2237-9843 